contain less than 80 per cent nickel, the maximum being about 2 per cent at 45 per cent nickel.

The alloys were melted and solidified in vacuo, annealed in a vacuum for seven days at $900^{\circ} \mathrm{C}$., reduced in thickness by 50 per cent by hammering at room temperature and then annealed in vacuo at temperatures between $700^{\circ}$ and $970^{\circ} \mathrm{C}$. for periods of up to $4,175 \mathrm{hr}$. Density measurements were made from time to time. It has been found that the alloys grow progressively, the amount of growth depending on the temperature of annealing and number of lattice vacancies.

The accompanying photograph shows the micro structure of an alloy containing 80 per cent copper after annealing for $4,175 \mathrm{hr}$. at $900^{\circ}$ C., during which treatment its volume increased by about 4.5 per cent. It will be seen that considerable micro porosity has developed during treatment. Almost all the porosity occurs in crystal boundaries with very little at twin boundaries or in the crystals.

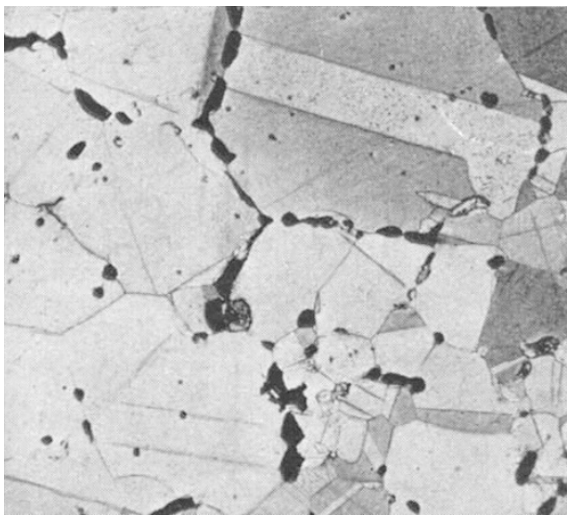

Micro porosity developed in $82 / 20$ copper-nickel alloy by prolonged annealing in vacuo. $\times 150$

Alloys containing less than 20 per cent copper, in which there are comparatively few vacancies, show less than $0 \cdot 1$ per cent growth under similar conditions.

Department of Metallurgy,

E. C. Ellwood

King's College (University of Durham),

Newcastle upon Tyne 1. April 7.

${ }^{2}$ Ellwood, E. C., Nature, 168, 722 (1949) ; J. Inst. Metals, 80, 217 $(1951-52)$.

Ellwood, E. C., and Bagley, K. Q., J. Inst. Metals, 80, 617 (1952).

\section{Spiral Growth on Graphite}

SPIRAL growth patterns have been observed on natural graphite. Typical spirals are shown in the accompanying photographs. The spirals have been predominantly hexagonal, although some with curved edges, particularly at the centre of the spiral, have been noted. The step-heights vary widely; the stepheight of the spiral shown in (b) is about $500 \mathrm{~A}$., those in (c) and (e) are apparently many orders larger. Photograph $(d)$ shows a double spiral and serves at the same time to give an idea of the density of spiral patterns. Areas have been noted in which the density of spirals is of the order of $10^{4}$ per cm. ${ }^{2}$.

Of the graphites studied, those which lend themselves best to the observation of spirals have been obtained from the crystallized limestones of the Grenville series ranging from the Adirondacks to north of Quebec. T'he spiral patterns are observed on the natural surfaces of the embedded graphite and also on surfaces exposed by carefully separating the graphite layers. No spirals have been observed on the surface of the limestone at the point from which the graphite is removed. Spirals have not been observed on samples of graphite obtained from Ceylon, nor from columnar graphite from Quebec. Neither of these samples has the distinct sheet-like structure of the Grenville series graphite. It is not possible yet to determine whether it is simply more difficult to resolve the spirals or whether they are not present on such samples.

The observation of growth spirals on graphite may be taken as evidence-in the same sense at least as has been established for silicon carbide ${ }^{1}$ in particular - that graphite may grow from screw dislocations. It is believed that certain structural problems in graphite may be clarified knowing that serew dislocations may be present. Thus, the polytypism in graphite may be developed along lines similar to those applied to the problem in silicon carbide ${ }^{2}$.

As developed a priori, the theory of crystal growth by screw dislocations is considered to pertain to growth under somewhat restricted conditions ${ }^{3}$. If spiral growth on graphite is limited to graphites from certain localities, the observation of spiral growth may be of assistance in interpreting the geological origin of graphites.

General Electric Research Laboratory,

\section{F. HUBbard HoRN}

Schenectady, New York. April 2.

1 Verma, A. R., Phil. Mag., 42, 1005 (1951).

a Frank, F. C., Phil. Mag., 42, 1014 (1951).

${ }^{3}$ Frank, F. C., Disc. Farad. Soc., No. 5 (1949). 